\title{
Cultural Expressions In Architecture - A Case Of Manapad In The Coastal Stretch Of Tuticorin
}

\author{
Dr.P.Jayasudha ${ }^{1}$, Ar.Tony Marcel Nisha ${ }^{2}$, \\ ${ }^{I}$ Dean, School of Architecture, Periyar Maniammai University, Thanjavur, Tamil Nadu. \\ ${ }^{2}$ Research Scholar, Department of Architecture, Periyar Maniammai University, Thanjavur, Tamil Nadu.
}

\begin{abstract}
Through architecture it's possible to gauge many things about a culture, such as lifestyle, artistic sensibilities and social culture". Residential architecture evolved basically for the need for shelter, to protect people from harsh weather conditions and other disasters. They built these shelters based on the climate, available materials, known techniques, their culture, lifestyle and socio - economic factors. Climate plays a major role in deciding the house forms in a place like the roof forms in a shelter, to an extent the size and volume of spaces, sequence of spaces and material usage too. However it is culture which details out the treatment or articulation of a built form. The size of the family units, the spaces which they use, the way their food is prepared, the way they eat, the way they interact, the work they do, how they do it etc., will all affect the layout and size of buildings. In certain places the dwelling units are clustered. These clusters might contain people belonging to the same family, or same caste or clan or even of the same occupation. One dwelling unit might be used by one family or several dwelling units by the same family itself. All these totally depend upon culture, these dwelling units can either be demarcated, separated from the other units or can also share a common platform etc. Buildings from the same climatic region are different and unique as a result of prevailing cultural conditions. Culture is not a constant. It keeps changing and also accommodates changes. People tend to have changes in their culture, due to the influence from neighbouring cultures or occupation or from any other parameters. It hence accepts changes so as to satisfy the current need of people. Thus vernacular architecture which is built based on culture also accommodates changes and is hence flexible. This is one of the main reasons for it to survive till date. This paper aims to illustrate the cultural expressions in architecture by analysing the architectural elements and details at all levels, from settlement to individual built form and till the element level. For the purpose, a case study of Manapad, located in the coastal stretch of Tuticorin, South India, which has a unique sustainable and cultural significance is studied.
\end{abstract}

Keywords: Culture, Climate, Tradition, Vernacular architecture

\section{Introduction}

Vernacular architecture is the architecture of the locals. It is built by the locals and reflects the needs, function, their culture, geographical location, historical context etc. [Engin $\mathrm{N}$ et al, 2007]. Hence it is generally accepted that traditional or vernacular architecture is well adapted to the dominant climate of that region [Sandeep Sharma et al 2013]. In some places, the cultural and social setup overshadows the climate oriented features. In these cases, the architectural features are designed to reflect their culture and traditions rather than be climate responsive [Manoj Kumar Singh et al, 2009]. Similar architectural solutions exist in similar climates across totally different and distant geographical locations but the character and the way these architectural solutions are treated, differ from one region to another, reflecting their culture and hence are region specific [Helena $\mathrm{C}, 1998]$. This is because when people migrated from one place to another, they also carried their style of house form, because they considered their house form as a symbol of their culture [Amos Rapoport]. In certain cases their architectural styles got adapted while in certain cases they accommodated changes so as to adapt themselves to that place. Thus culture is something that accommodates changes but the changes happen very slowly and are not changed overnight [Stephen F, 1994]. Vernacular architecture thus has maximum adaptability and flexibility. This is one reason why vernacular architecture can exist for a longer period than the modern architecture. Amos Rapoport says "Culture is a whole way of life". It is a complex of beliefs, traditions, religious or social group and various races [Paul Edwards, 1967]. It is therefore understood as involving more than the values and needs of people but the entire way of life [Wilhelm Allan Neilson, 1941]. Tradition is dynamic as it changes with people's desires or cultural expressions. Hence vernacular architecture which respects culture is also dynamic [Sandeep Sharma et al, 2013]. Amos Rapoport proposed five aspects of culture which greatly influences the architectural form. They are, the ways basic needs are fulfilled, the family structure and hierarchy, the varied role of women within society, attitudes toward privacy, and social interaction. Culture is a broader domain and hence cannot be directly associated to architecture. It follows a lot of sub sects that affects architecture. They are kinship, family structure, roles, social network, status, identity etc. [Amos 
Rapoport, 1998]. Only after analysing the role of these sub sects in built form, we can understand the cultural expressions in architecture.

\section{Research Methodology}

The research is aimed at exploring the cultural expressions in the vernacular architecture of Manapad, by;

1. Documenting and analysing the place at settlement level and street level

2. Selecting, documenting and analysing any one residential unit in that region.

\section{Area of Study:}

Manapad is about 58kms south of Tuticorin, a famous port town in South India.
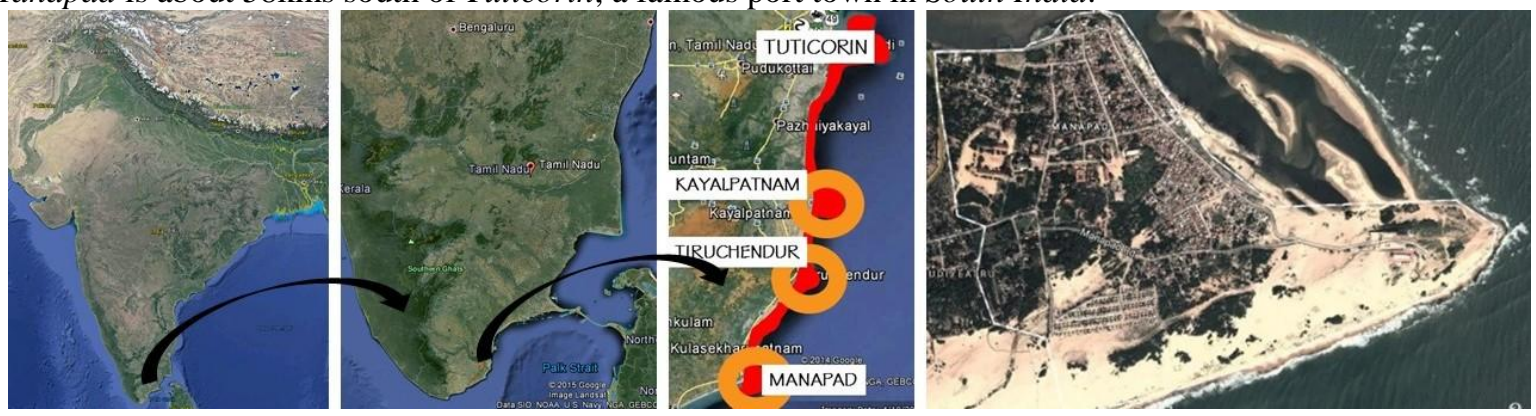

Fig. 1. Map showing the location of Manapad

The coastal stretch of Manapad extends to about $3145 \mathrm{~m}$, and has a total area of 260 acres. It is a Christian populated area with a total population of about 6000 inhabitants. It is close to Tiruchendur, one of the famous Hindu religious towns in South India and Kayalpatnam or Korkai, a Muslim town and an ancient silk route port. It has a very unique culture, because of the Portuguese invasion during the $14^{\text {th }}$ century and trade links with Ceylon (present Sri Lanka). The village remained intact until 1540's and later on Indo-Portuguese style of Architecture came into existence. This unique culture is revealed in their architecture. Their dwellings reflect occupant's activities in their lives while adapting to the warm and humid climate.

\section{Culture Of Manapad}

Manapad has a distinct culture as it has gone through many changes in its religion, occupation etc. It has a cultural mix of India, Portugal and that of Ceylon. They adopted European outlook but did not cut themselves completely from the cultural roots of India. This resulted in a cultural mix which can be seen even through their external appearances like dressing style, food, their language (Tamil accent) etc. Privacy is one of the main character that can be seen in traditional houses but their houses had an extroverted plan, with lots of semi-open and open spaces facing the streets and sea to provide good views.
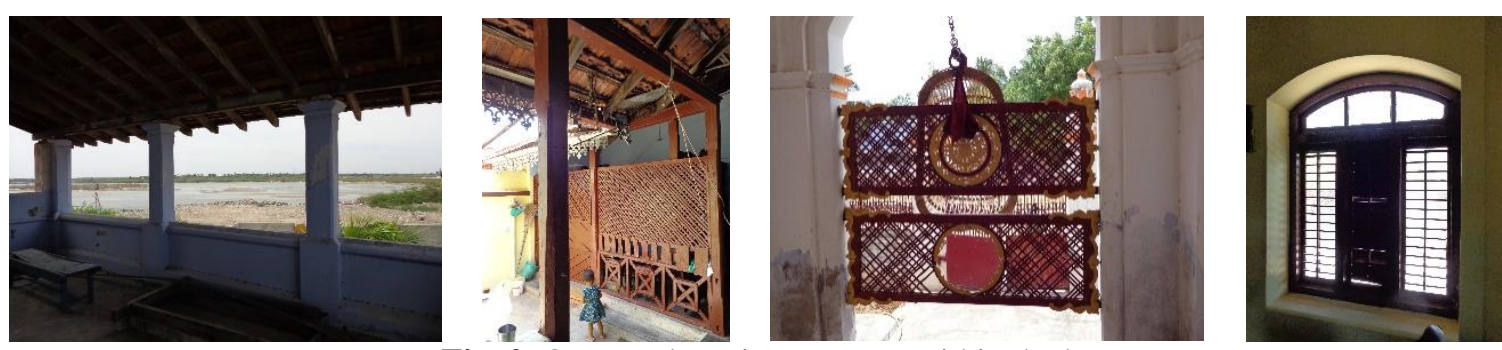

Fig. 2. Open and semi open areas within the house

They tend to live a luxurious life, and that nature is reflected even in their built forms. They build massive houses, with detailed and rich ornamentations. Separate spaces are allocated for separate functions unlike the general traditional houses which have multi activity generating spaces. The materials used for construction are also mostly imported materials, like the use of teak wood which is imported from Ceylon etc. The use of locally available materials is minimal. One of the interesting and significant features of vernacular houses is their built in furniture, whereas on the contrary, these houses have luxurious ornamented furniture that are imported. They still have strong ties with Ceylon through trade and still some of their relatives stay and also own property in Ceylon. Hence import of materials is very easy. They tend to show off their status, power or wealth and strictly adhere to demarcation of classes. Women are treated equal to men and hence there are no segregation of male-female spaces. 


\subsection{Religious context:}

Manapad is said to have practiced Hinduism at the very beginning. It is famous for its coral reefs and pearl oysters and hence the Muslim rulers came to this place. This introduced turmoil into the place and they also tortured the natives by imposing severe tax and punishments. This is one of the reasons why Muslim religion is still devoid in this place. The advent of Christianity was due to the arrival of Dutch sailors and St. Francis Xavier. This transformed the settlement in every sphere of influence - culture, architecture, lifestyle and development which is evident today. Thus the village is inhabited predominantly by Christians.

\subsection{Beliefs and practices:}

The people of Manapad are generally religious and give it their first priority than others. The village has two parishes, The HOLY GHOST CHURCH and St. JAMES CHURCH and two other shrines HOLY CROSS CHURCH and St. XAVIERS CAVE, which are frequently visited by tourists from around the country. The feasts of all the three churches are celebrated annually in a grand manner. There is a shrine in every street intersection, which is built and maintained by the people belonging to that street. Prayers are performed at the dawn of every day and are conducted by women. At night this space is converted into a place of social gathering for chit chats etc. In addition to this, there is also a worship place in every house, irrespective of the differences in the community. Only the scale of the space, whether a separate room is allotted or a space within a room differs.

\subsection{Social background, custom, lifestyle $\&$ family structure:}

Stratification based on both socio-economic classification and community/ caste, can be seen dominantly in the village. The village has a Ceylon-Portuguese cluster, Nadar cluster and Paravas cluster. Each of these clusters have a different culture which is reflected in their architecture too. The different churches built by disparate super ordinates, also dissolved the society furthermore. Different lifestyle and family structure have been adopted by this village, even though there's commonality in religion and the predominant occupation being fishing. For eg. Fishermen community people live in close clusters near the sea. These clusters comprises of the people belonging to the same family. Their common workplaces like auction yards, fishing net stitching sheds etc. are all situated opposite to their dwelling spaces and near to the sea. The spaces in between the clusters and the surrounding open spaces are vibrant and used for multi activities like social gathering spaces, play areas etc. They had a close bonding between the people of their community and the spaces related to their occupation. Whereas the traders who belong to the upper class, lived in the highland, and were compounded individually and were completely secluded from each other. They liked to live in close connection with nature and the surrounding environment, by bringing in semi-open and open spaces, but liked to conceal them from their neighbours. They lived a more sophisticated life when compared to the other community people. They also liked to show off this nature whenever and wherever possible.

\subsection{Settlement pattern:}
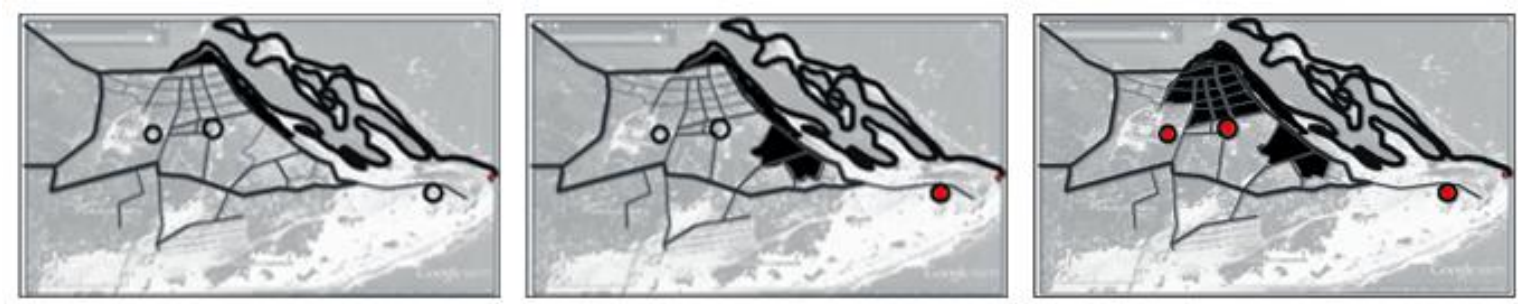

Fig. 3. Maps showing the growth of the village.

- The first settlement grew in an organic way along the coastal line, where fishing was the primary occupation.

- The second settlement grew in clusters, where their occupation supported fishing activities like boat building, basket weaving etc.

- The third settlement was planned in a proper grid pattern, with the churches on one side and with the backwaters on the other side. This settlement was occupied by the high class people. This area is situated at an elevated land and hence facilitated good views too.

\subsection{Street pattern:}

- The main streets are the traditional streets which facilitated chariot movement during church festivals and hence were wide. These roads are now used for vehicular usage.

- The next category of roads are slightly lesser in width and connects the clusters with the primary or main streets 
- The final category of roads are very small and segregates various clusters from one another.

\subsection{Special features in street:}

- All the street intersections have a small shrine / grotto, which is built and maintained by the residents of that street itself. This kind of grotto can be seen in all the streets, irrespective of the type of clusters, which is another unique character of Manapad. This character is said to be influenced from the neighbouring settlement in that area. Areas like Tiruchendur, Kulashekarapatanam etc. usually have Hindu shrines at every street intersection. This character has been adopted, altered as per their religion and is being followed till the present day.

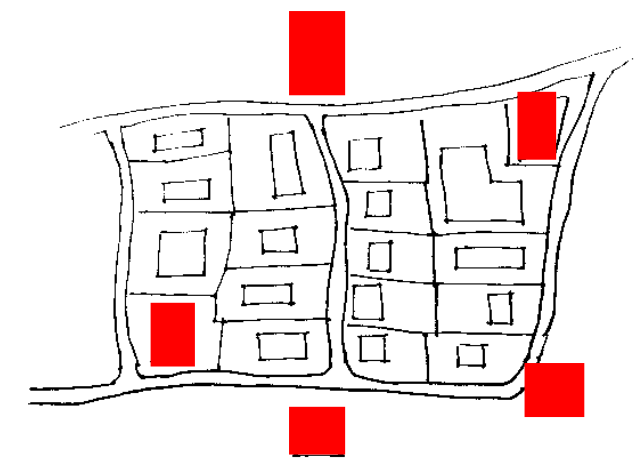

Fig.4. Map showing the location of grotto at every street intersection

\section{Analysis Of The Case Example}

The sample selected for study is 120 years old and is situated in the properly planned grid iron settlement area of Ceylon-Portuguese cluster. It is located at the intersection of two streets, adjoining a grotto and a small shrine. This house is situated on the banks of the backwater. It has two different cultural influences (Sri Lanka, Indo-Portuguese) in its architecture. These houses have an extroverted planning with lot of open and semi-open spaces like Balcoes, verandas, and Balconies etc. which faces the street and sea. Balcoes are nothing but covered porches which are commonly found in the facades of traditional Portuguese houses. The balcoes were the places where men and women could sit together and chat with neighbours or just enjoy the evening breeze.

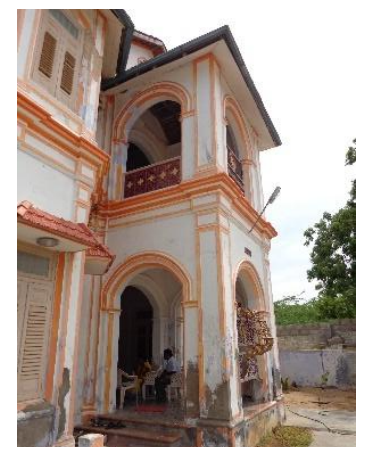

Fig 4. a.Balcoes and balcony spaces

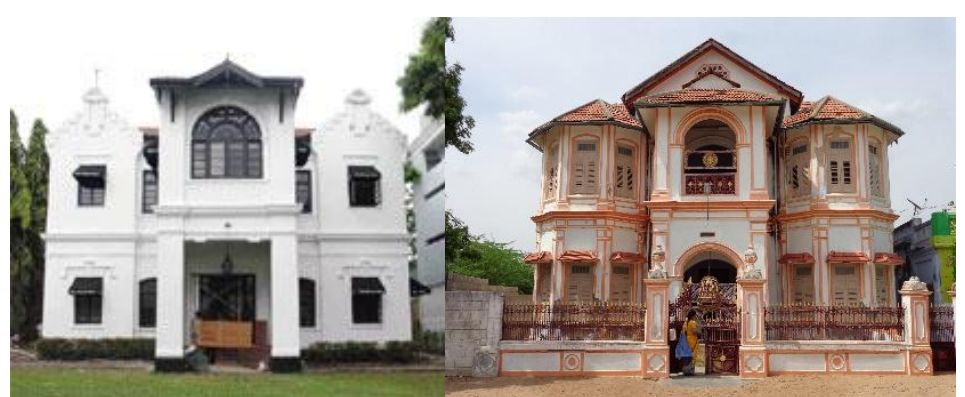

b. Elevation of a Ceylon Portuguese house in Ceylon and in India

The façade of most houses are symmetrical with tripartite divisions. Large ornamental arched windows with stucco mouldings were present in the houses. These mouldings and other ornate elements and details belonged to the Portuguese architecture. Railings were the most intricate element in the house.

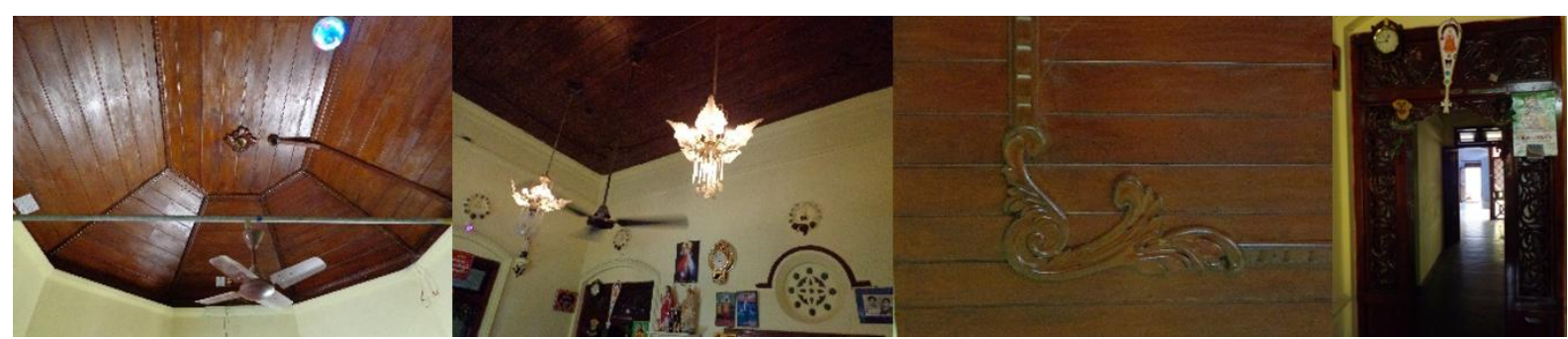

Fig. 5. Ornamentations in false ceiling and doors. 
Almost all houses have a false ceiling of wood. A very peculiar feature that is found in almost all the houses belonging to the Ceylon cluster, is the presence of a window between the Master bedroom and the guest bedroom, which is a direct reflection of Portuguese culture, but these windows are now covered or left closed which is a reflection of Indian culture. Thus the house as a whole is a result of the fusion of all three cultures.

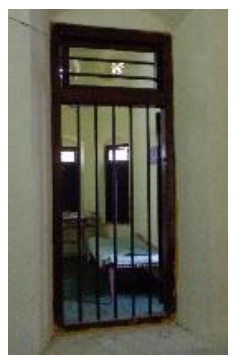

Fig.6. Window between master bedroom and guest bedroom

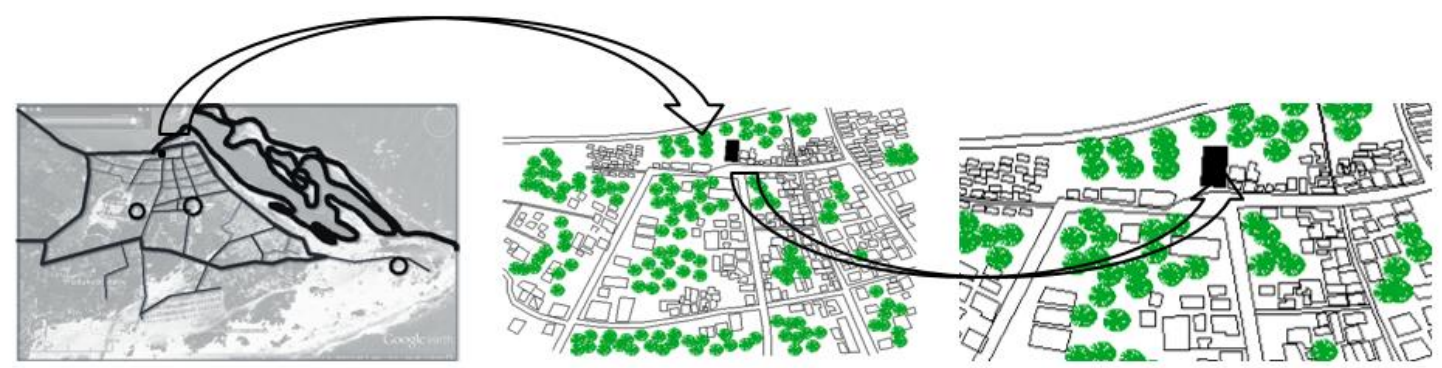

Fig.7.Map showing location of case example

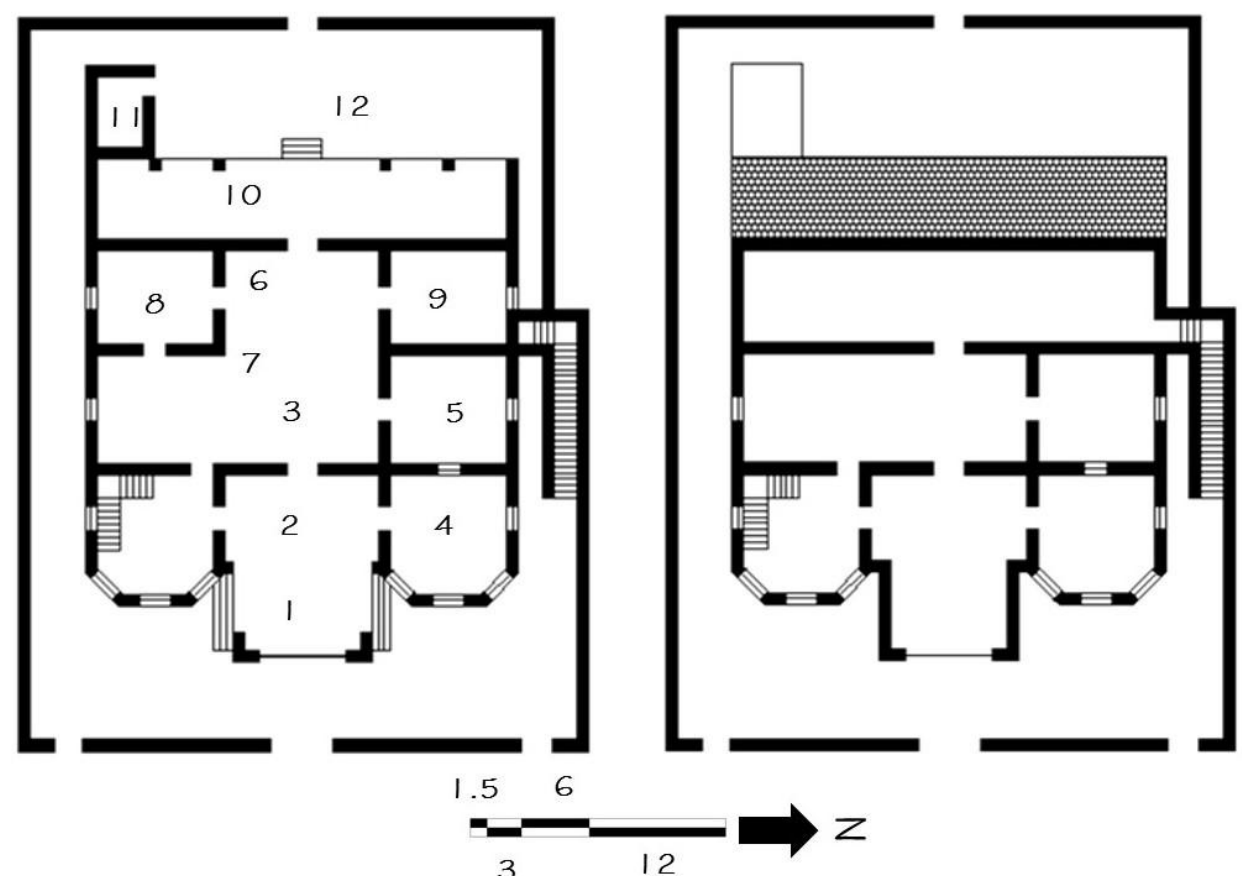

Fig. 8.a. Ground floor plan

8.b. First floor plan

$\begin{array}{llll} & \text { 1. ENTRANCE } & \text { 5. BEDROOM } & \text { 9. KITCHEN } \\ \text { LEGEND: } & \text { 2. VISITORS ROOM } & \text { 6. DINING SPACE } & \text { 10. CORRIDORED VERANDAH } \\ & \text { 3. LIVING ROOM } & \text { 7. WORSHIP SPACE } & \text { 11. TOILET/ BATHROOM } \\ & \text { 4. ELDERS BEDROOM } & \text { 8. STORE ROOM } & \text { 12. BACKYARD }\end{array}$




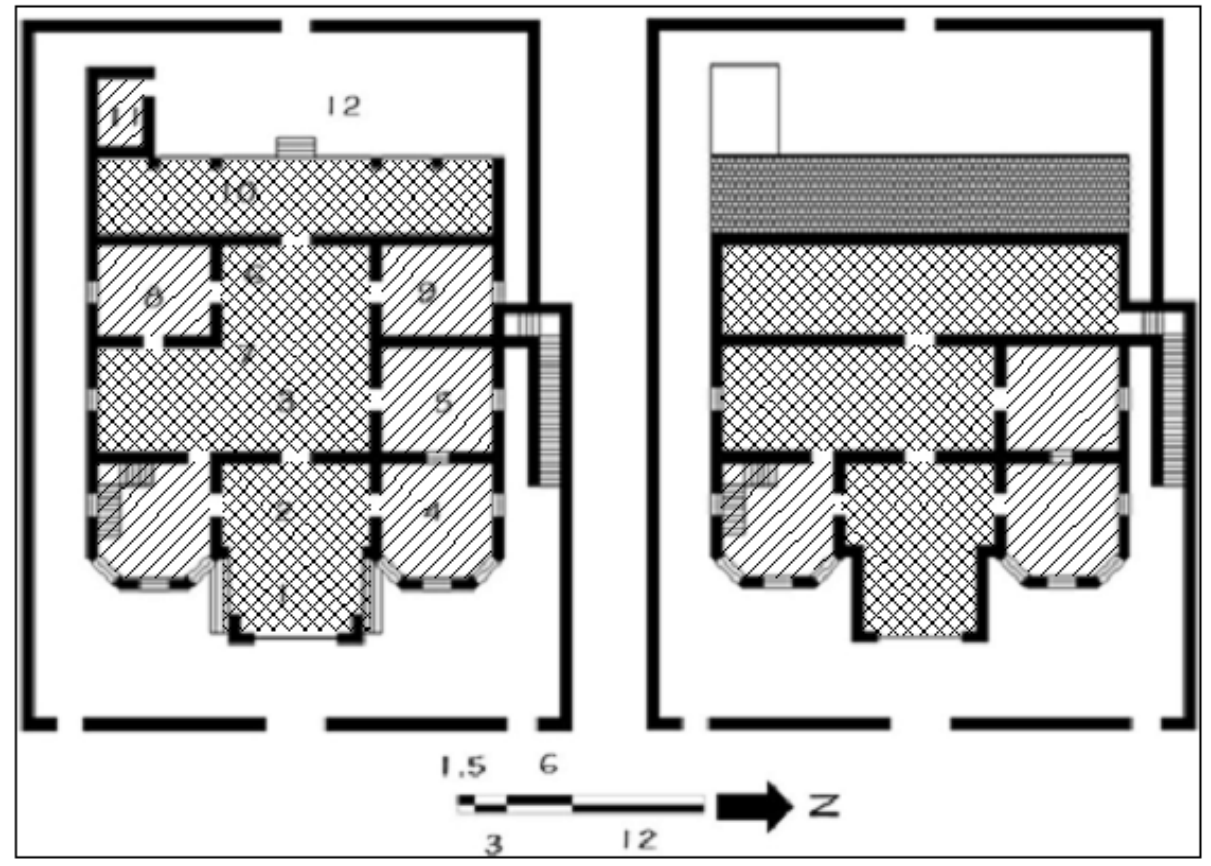

Fig.9. a. Plan showing single and multi-activity spaces within the house

\section{LEGEND: 1 . WA SINGLE ACTIVITY SPACES \\ 2. MULTI ACTIVITY SPACE}

\subsection{Religion:}

\section{Culture And Architecture}

The village is a Christian dominated city. Different churches were built in different clusters. This created a division among the populace with respect to the church they were entitled to. There are also Grottos at the intersection of every street. There is a separate worshiping place within the house. This shows their closeness in their religion. The people also celebrate various church feasts throughout the year. Marriage and other rituals takes place according to the Indo- Portuguese custom.

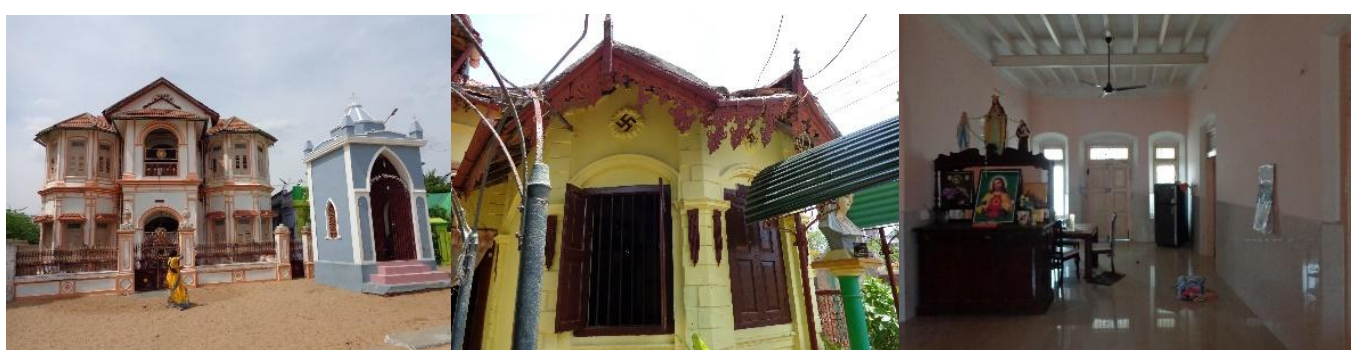

Fig.10.a.Grotto at street

10.b.Grotto at house front yard 10.c. Worship space at house

\subsection{Occupation:}

Manapad is a coastal village and hence developed based on their occupation, which is fishing and pearl culture. This then expanded further to foreign trades and foreign cultures came into existence. The connection with Ceylon through trade is reflected by the style of architecture, spatial organisation and the material that they employ.

\subsection{Tradition, beliefs and customs:}

- The settlement pattern itself shows the demarcation of different community and reveals the strong belief in community stratification. Different communities have different settlement patterns and this demarcates them from one another.

- The connecting window between the master bedroom and guest room shows the close relationship between the family members and the close bonding between each other. 
- $\quad$ Separate entry for servants were provided, as they strictly adhered to class stratification

- The house was compounded on all four sides and hence lacked socialness with people but had lots of open and semi open spaces which facilitated close connection with nature and surroundings.

- Detailed ornamentation was used throughout the house and acted as symbol to show off their power, luxury and wealth.

\section{Conclusion}

Culture and climate plays a vital role in Vernacular architecture. This is revealed through the analysis of vernacular architecture of Manapad. Its architecture reflects the sensitivity to its unique culture from the settlement level to an individual built form level. They are also sensitive to the socio needs of the users through the provision of open and semi-open areas (verandas, balcoes and balconies). The houses reveals its flexible nature by adapting to tamil culture in Ceylon Portuguese houses. Thus the architecture of Manapad is purely the result of their cultural expression.

\section{References}

[1]. Engin N, Vural N, Vural S, Sumerkan MR. Climatic effect in the formation of vernacular houses in the Eastern Black Sea region. Building and Environment 2007;42(2):960-9.

[2]. Helena C. Bioclimatism in vernacular architecture. Renewable and Sustainable Energy Reviews 1998;2(1-2):67-87.

[3]. Manoj Kumar Singh, Sadhan Mahopatra, Atreya M.K. Solar passive features in vernacular architecture of North East India. Building and Environment (2009) ; 44 :878-888.

[4]. Amos Rapoport House form and Culture, published by: Prentice Hall, Inc. Englewood Cliffs, NJ 07632 USA.

[5]. Stephen F, Kenney B.S. Cultural Influences on Architecture. M.arch Thesis, December, 1994,Texas Tech University.

[6]. Paul Edwards, ed.. The Encvclopedia of Philosophv (New York: The Macmillan Company \& The Free Press, 1967$), 273$.

[7]. Wilham Allan Neilson, Ph.D., ed., Webster's New International Dictionarv of the English Language (Springfield, Massachusetts: G\&C Merriam Company, Publishers, 1941), 643.

[8]. Amos Rapoport, Using Culture in Housing Design, Housing and Society, Volume 25, No. 1\&2, 1998.

[9]. Sayigh A, Marafia H. Vernacular and contemporary buildings in Qatar. Renewable and Sustainable Energy Review 1998;2(12):25-37.

[10]. Sandeep Sharma and Puneet Sharma ,Traditional and Vernacular buildings are Ecological Sensitive, Climate Responsive DesignsStudy of Himachal Pradesh International Journal of Chemical, Environmental \& Biological Sciences (IJCEBS) Volume 1, Issue 4 (2013) ISSN 2320-4079; EISSN 2320-4087 